\title{
Performance evaluation and flow visualization of a MEMS based vaporizing liquid micro-thruster
}

\author{
J.W. Cen ${ }^{\mathrm{a}}$, J.L. Xu ${ }^{\mathrm{b}, *}$ \\ a Micro Energy System Laboratory, Guangzhou Institute of Energy Conversion, Chinese Academy of Sciences, Guangzhou 510640, PR China \\ ${ }^{\mathrm{b}}$ The Beijing Key Laboratory of New and Renewable Energy, North China Electric Power University, Beijing 102206, PR China
}

\section{A R T I C L E I N F O}

\section{Article history:}

Received 20 December 2009

Received in revised form

27 March 2010

Accepted 8 April 2010

Available online 24 April 2010

Keywords:

Micro-satellite

Vaporized liquid micro-thruster

MEMS

Flow pattern

Instability

\begin{abstract}
A B S T R A C T
MEMS micro-thruster is promising for future applications in precision formation flying missions. This paper presents performance evaluation and two-phase flow pattern visualization of a vaporized liquid micro-thruster (VLM). Micro-thrust force of several milli-Newtons was measured by a test rig with a lever. Flow patterns in the micro-thruster chip were visualized by a high speed camera bonded with a microscope. We found that flow patterns influenced its specific impulse and there were several types of flow boiling patterns in the thruster chip. Thrust instability was discussed as well. The results are helpful to understand flow characteristics of a VLM and improve its performance.
\end{abstract}

(c) 2010 Elsevier Ltd. All rights reserved.

\section{Introduction}

Recently, due to the advance made by technologies over the past decade, a new trend is to use micro or nano-satellites in more demanding space missions such as space science, earth observation, flying formation and space surveillance. They have advantages of small volume, light weight, short development cycle and low cost [1]. Missions such as flying formation require high precision attitude control system. Micro- and nano-satellites having orbital maneuver ability can serve as inspectors to surround a space station or a spacecraft.

However, their orbit and attitude are usually disturbed due to the solar radiation pressure and non-uniform gravity field [2]. Therefore, it is crucial for these satellites to have flexible and precise orbital maneuver and attitude control ability. Hence highly efficient micro-thrusters are required to achieve this ability.

\footnotetext{
* Corresponding author. Tel./fax: +862087057656.

E-mail address: xujl@ms.giec.ac.cn (J.L. Xu).
}

Micro-thrusters have been paid great attention by scientists in many countries. Several types of micropropulsion systems are proposed, such as single phase cold/ hot flow micro-thruster [3-5], solid propellant micro-thruster array [6,7], pulsed plasma micro-thruster [8], electrospray micro-thruster [9], etc.

Compared to single phase cold/hot flow micro-thrusters, propellant of VLM can be stored in low pressure and light weight fuel tank, but VLM will consume more electric energy to vaporize liquid propellant. While micro-thrusters using solid materials can start only one time, VLM can be restarted easily for thousands of times depending on the quality of the valve and volume of fuel storage.

Although for the time being, most of the microsatellites choose liquefied gas thrusters, such as liquefied butane propulsion system in SNAP-1 [3], liquefied $\mathrm{SF}_{6}$ in CAN4\&5 [4], micro-liquid fuel thruster is still promising due to its high energy density and low pressure storage. Particularly, micro-thrusters based on the MEMS technology have many advantages, such as low cost, small volume, light weight and convenience to integrate with other MEMS components. They can be employed as orbital control as well as attitude control actuators. 


\begin{tabular}{|c|c|c|c|}
\hline \multicolumn{2}{|c|}{ Nomenclature } & $v_{e}$ & nozzle outlet velocity $(\mathrm{m} / \mathrm{s})$ \\
\hline$A$ & cross section area $\left(\mathrm{m}^{2}\right)$ & & \\
\hline C & mass concentration $(\mathrm{kg} / \mathrm{kg})$ & \multirow{2}{*}{\multicolumn{2}{|c|}{ Non-dimensional numbers }} \\
\hline$C_{0}$ & stagnation sound speed (m/s) & & \\
\hline$c c$ & cubic centimeter & \multirow[t]{2}{*}{ Bo } & \multirow[t]{2}{*}{ boiling number } \\
\hline$D_{h}$ & hydraulic diameter (m) & & \\
\hline$F$ & thrust force $(\mathrm{N})$ & \multirow{2}{*}{\multicolumn{2}{|c|}{ Greek symbols }} \\
\hline$F$ & frequency $\left(s^{-1}\right)$ & & \\
\hline$G$ & mass flux $\left(\mathrm{kg} /\left(\mathrm{m}^{2} \mathrm{~s}\right)\right)$ & \multirow{3}{*}{$\begin{array}{l}\gamma \\
\sigma\end{array}$} & \multirow{3}{*}{$\begin{array}{l}\text { specific heat ratio } \\
\text { surface tension }(\mathrm{N} / \mathrm{m})\end{array}$} \\
\hline$g$ & acceleration due to gravity $\left(\mathrm{m} / \mathrm{s}^{2}\right)$ & & \\
\hline$h$ & specific enthalpy $(\mathrm{J} / \mathrm{kg})$ & & \\
\hline$I_{s}$ & specific impulse (s) & \multirow{2}{*}{\multicolumn{2}{|c|}{ Subscripts }} \\
\hline$\dot{m}$ & mass flow rate $(\mathrm{kg} / \mathrm{s})$ & & \\
\hline$M_{e}$ & nozzle outlet Mach number & & \\
\hline$M$ & molecular weight (kg) & $f$ & fluid \\
\hline$P$ & total pressure $(\mathrm{Pa})$ & $g$ & gas \\
\hline$p_{e}$ & nozzle outlet pressure (Pa) & $\max$ & maximum \\
\hline$q$ & heat flux $(\mathrm{J} / \mathrm{kg})$ & ONB & onset nucleate boiling \\
\hline$R$ & gas constant $(\mathrm{J} / \mathrm{kg} \mathrm{K})$ & sat & saturation \\
\hline$T$ & temperature $(\mathrm{K})$ & $t$ & nozzle throat \\
\hline$T_{0}$ & stagnation temperature $(\mathrm{K})$ & & \\
\hline
\end{tabular}

Hitt et al. [2] developed a prototype monopropellant MEMS thruster that used the catalyzed chemical decomposition of high-concentration hydrogen peroxide as a propulsion mechanism. The targeted thrust level was approximately $500 \mu \mathrm{N}$. The primary difficulty encountered had been that of achieving complete chemical decomposition of the propellant within the MEMS geometry.

Mueller et al. [10] described the design and fabrication of a proposed VLM concept for use as an attitude control device on new generations of very small spacecraft, ranging in mass between 1 and $20 \mathrm{~kg}$. Their attention was focused on thermal design aspects to limit power requirements to values less than $5 \mathrm{~W}$, requiring specially contoured substrate shapes and packaging of the thruster chip.

Maurya et al. [11] have reported a silicon MEMS vaporizing liquid micro-thruster (VLM) with an internal p-diffused micro-heater. The VLM consisting of two micro-machined, bonded silicon chips produced thrusts in the range of $5-120 \mu \mathrm{N}$ with a heater power of $1-2.4 \mathrm{~W}$ at a water flow rate of $1.6 \mu \mathrm{s} \mathrm{s}^{-1}$ using an exit nozzle of throat size $30 \mu \mathrm{m} \times 30 \mu \mathrm{m}$. The measurement had been carried out using a sensitive cantilever and a laser based lamp-and-scale arrangement. The internal micro-heater was expected to yield a higher efficiency compared with the external micro-heater. They also performed a theoretical simulation of the VLM involving complex numerical 3D micro-fluidic, thermodynamic and electro-thermal solutions [12].

Mukerjee et al. [13] also developed a similar VLM. The vaporization chamber, inlet and exit nozzles were fabricated using anisotropic wet etching of silicon. With a $5 \mathrm{~W}$ heater input, injected water could be vaporized for input flow rates up to a maximum of $0.09 \mathrm{~cm}^{3} / \mathrm{s}$. Experimental testing produced thruster force magnitudes ranging from $0.15 \mathrm{mN}$ to a maximum force output of $0.46 \mathrm{mN}$ depending on fabrication parameters.

Ye et al. [14] fabricated and tested a VLM. The microthruster was designed to operate in pulse mode. During each period, an electric pulse was applied to the microresistor to heat the water in the chamber to vaporize it into high-pressure gas. A thrust was then produced as the gas exits through the nozzle. Test results showed that for a single micro-thruster with a pulse power of $30 \mathrm{~W}$, the total impulse produced in a second was more than $0.2 \times 10^{-6} \mathrm{~N} \mathrm{~s}$.

Chen et al. [15] investigated flow characters of a MEMS VLM. They found that there were four distinct flow patterns observed including snake flow, vapor-droplet flow, vapor-droplet-jet flow, and vapor flow. To prevent the failure of micro-thruster chip from generating snake flow, the heating treatment of an empty micro-thruster chip at $300^{\circ} \mathrm{C}$ for $2 \mathrm{~h}$ was the key factor.

Compared with thrusters of normal size, fluid flow in the micro-thruster chip shows different characteristics due to its large specific surface area and viscous effect at micro-scale. Although there have been many research papers available in the literature about micro-scale fluid flow in micro-channels [16,17] and micro-nozzles [18,19], few have related flow patterns with thrust performance. In this work, micro-thrust force and specific impulse of a VLM were measured, and the two-phase flow patterns were visualized by high speed camera bonded with a microscope. Three aspects of the micro-thruster were discussed: (i) performance, (ii) two phase flow boiling pattern, and (iii) instability. The results on these aspects will be helpful to understand characteristics and the design of liquid fuel micro-thrusters of high efficiency. 


\section{Experiment detail}

\subsection{Fabrication of MEMS thruster chip}

A micro-thruster chip was fabricated by standard MEMS technology. As shown in Fig. 1, the chip consists of two layers: pyrex glass and silicon substrate. They were bonded together by anode bonding methodology. The $120 \mu \mathrm{m}$ deep fluid grooves were etched on the silicon substrate by deep inductively coupled plasma (ICP) method. The grooves include a rectangular inlet, nine parallel micro-channels and a convergent-divergent nozzle. Micro-channels have a large ratio of surface to volume, which will improve heat transfer for VLM or enlarge catalytic surface for a $\mathrm{H}_{2} \mathrm{O}_{2}$ monopropellant micro-thruster if the inner surface of the micro-channels is sputtered with catalytic metal. The size of the throat section of the micro-nozzle is $150 \mu \mathrm{m} \times 120 \mu \mathrm{m}$. The roughness of the MEMS chip in micro-channel and micro-nozzle is about $10 \mathrm{~nm}$. Further information about
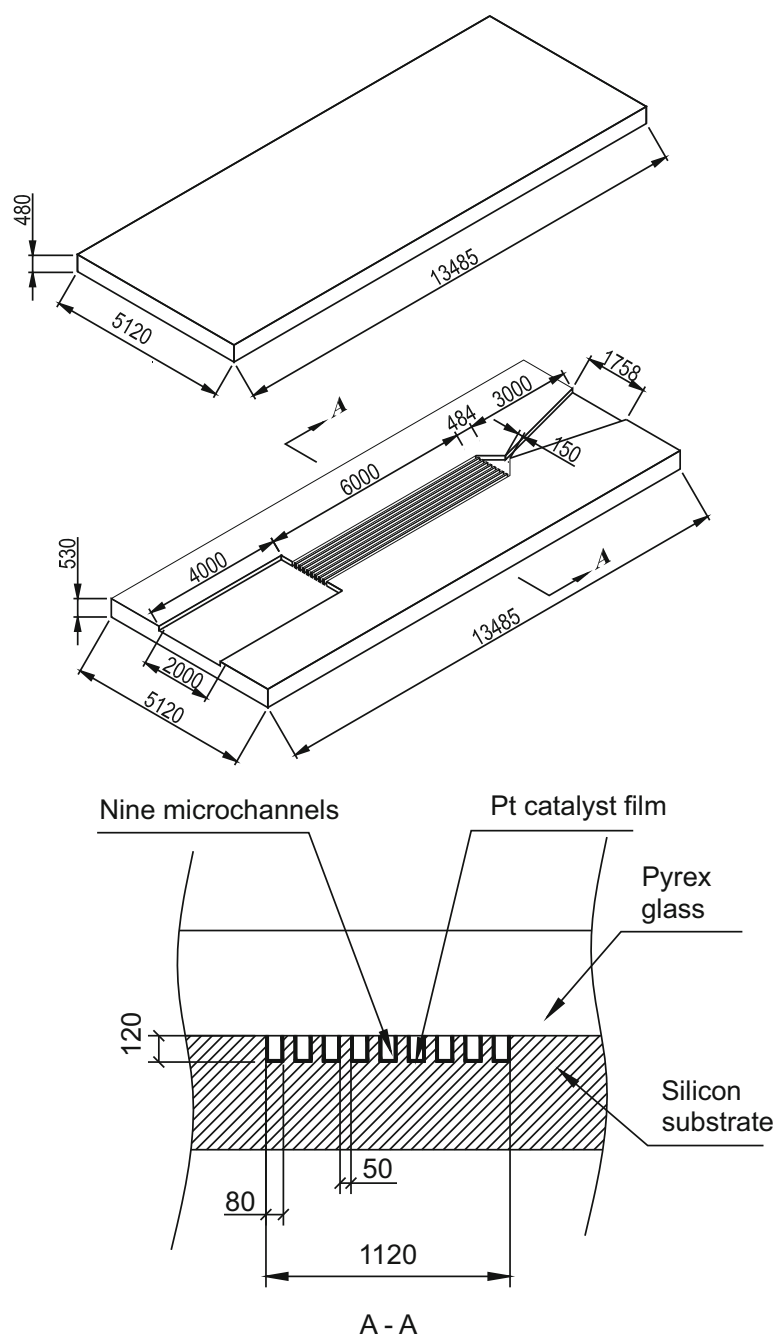

Fig. 1. Structure and size of the chip (unit: $\mu \mathrm{m}$ ). the fabrication can be found in previous works presented by the authors [20].

The chip was connected with a silicone tube. The outer and inner diameters of the tube are 6 and $4 \mathrm{~mm}$, respectively. The inlet of the chip was inserted into the tube about $3 \mathrm{~mm}$ deep. Then they were clamped together tightly for seal by a clip. Because the temperature of the small chip tends to fluctuate severely and is hard to be controlled, the silicon side of chip was smeared with heat conduction cream and sticks to a piece of copper. An electric heater was set inside the copper and temperature was monitored by a thermal couple. We have also performed experiment that micro-thruster chip was heated by a microfilm heater. The results show that the temperature of the chip will vary severely up and down and it is very hard to control the temperature stably because the thermal capacity of a small chip is too small to be well controlled in temperature. But it may be noted that a real micro-thruster will not be allowed to use such a heavy piece of copper as heater. Instead, a micro-heater, such as Pt film heater or polysilicon heater $[13,14]$, should be employed in the thruster chip.

Here, we must make it clear that the chip temperature in this paper refers to copper block temperature, which heats the chip. The outer surface temperature of the chip indeed varies at different locations due to phase change heat transfer inside. If a detailed chip temperature needs to be tested, an IR camera should be used instead of a thermocouple because the chip is made of silicon and is too small to be bonded with thermocouple.

\subsection{Performance test of the micro-thruster}

The micro-thruster sticking on a copper heater block was mounted on a slide track (not shown in Fig. 2). The track could carry it to move vertically or horizontally to adjust the relative position between the thruster and an impinging plate on the end of the lever, as shown in Fig. 2. The nozzle was $2 \mathrm{~mm}$ high above the impinging plate, as shown in Fig. 3. The micro-thruster spurted gas at the impinging plate and the resulting impinging force was enlarged by a lever. Then the enlarged force was sensed by a piezoelectric sensor set on the other side of the lever. The force sensor was only $5 \mathrm{~mm}$ away from the fulcrum, which was much shorter than the distance from the fulcrum to the impinging plate. The piezoelectric sensor induced electric charge. Then electric charge was converted to $0-10 \mathrm{~V}$ voltage by a Switzerland charge meter. Finally the voltage signal was transmitted to an Agilent data acquisition system.

The lever was submerged in vacuum oil to damp the vibration from circumstance. Small vibrations from the ground, for example someone running nearby, will result in large noise occurring in micro-thrust force signal. Therefore, we put the test rig on a bed of sponge to reduce disturbance from the ground. Furthermore, in order to reduce friction at the fulcrum, the lever was made of light weight material, such as aluminum alloy. The fulcrum was composed of two bearings of $2 \mathrm{~mm}$ internal diameter and a shaft. They were immersed in vacuum oil as well. 


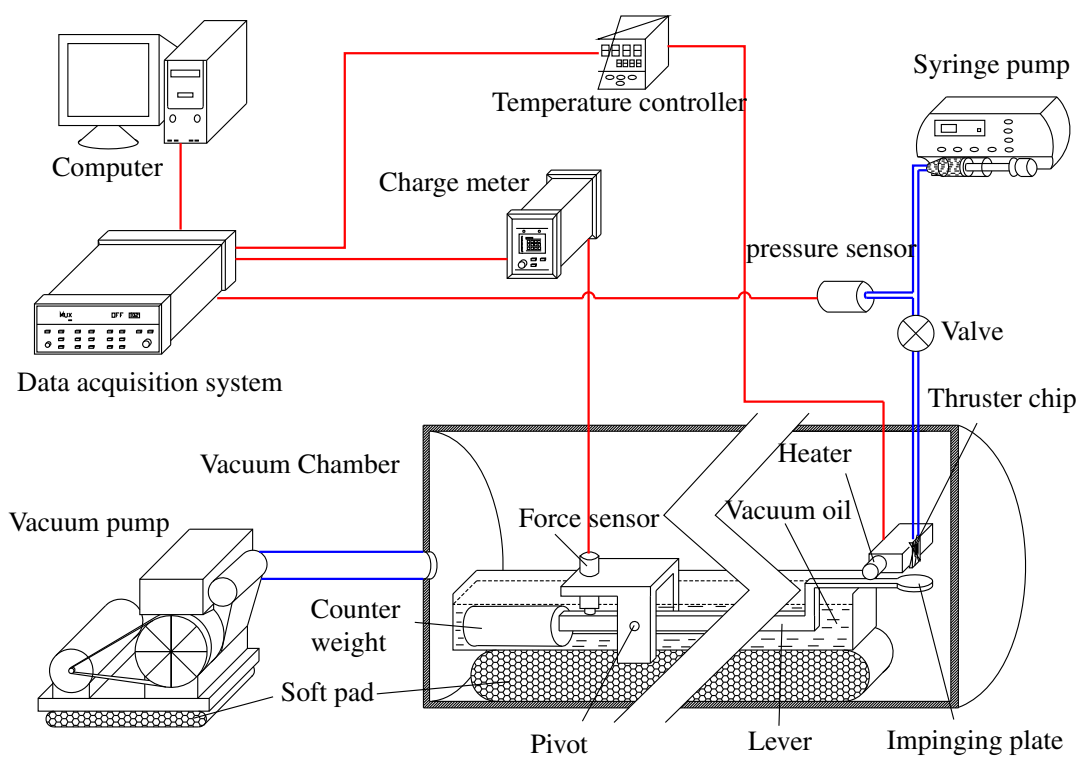

Fig. 2. Micro-thrust force test rig.

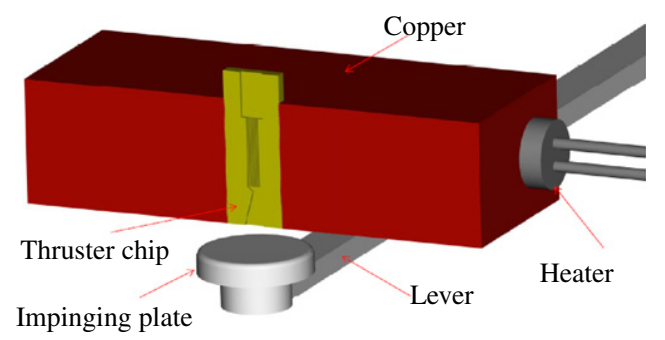

Fig. 3. Schematic of impinging force measurement.

Lubrication effect of oil further reduced the friction of the fulcrum. Experimental results have shown that noise signal was reduced greatly after using these damping facilities.

The test rig was put inside a cylinder of $21 \mathrm{~cm}$ outer diameter and $140 \mathrm{~cm}$ long. The cylinder was vacuumed by a vacuum pump with a pump rate of $15 \mathrm{~L} / \mathrm{s}$. Pressure in the cylinder could be kept below $20 \mathrm{~Pa}$ within all ranges of test conditions. Previous experiment has shown that background pressure less than several hundred pascals has little effect on micro-thrust test [21].

In fact, the measured force with the test method described above was impinging, not thrust force. As noted by Jamison et al. [22], when the thrust force is in micro- or nano-Newton scale, the connection of the thruster stand with its supply infrastructure becomes difficult to handle. In this method the thruster was not installed directly on the lever, then disturbances could not propagate through the connection pipe or wires to the lever. Thus, the thruster was allowed to be connected with hard metal pipe, or integrated with other components without any harmful effect. But this thrust test method also has its own defects: (i) impinging force is not equivalent to thrust force, and part of the jet from the nozzle does not impinge on the plate; (ii) if the thruster is too far away from the plate, the measured force is prone to be smaller than thrust force; if it is too close, the plate will alter the flow field of the jet severely and cause false measurement. Our previous works showed that impinging force was 1.5 times as large as thrust force when the nozzle outlet was $2 \mathrm{~mm}$ away from the impinging plate of $10 \mathrm{~mm}$ diameter [23].

\subsection{Flow visualization experiment}

Fig. 4 illustrates the flow visualization experimental set-up. The micro-thruster chip, stuck on a copper block, was placed inside a transparent vessel. The vessel was vacuumized by a vacuum pump. De-ionized water was pumped into the chip with a syringe pump. Flow patterns in the chip were recorded by a microscope bonded with a high speed digital camera. An electronic heater was fixed inside the copper block to control the chip temperature through a constant temperature control unit (PID) with an uncertainty of $0.5^{\circ} \mathrm{C}$. The inlet pressure was measured by a Setra pressure transducer (model 206) with an uncertainty of $1 \%$.

\section{Results and discussion}

\subsection{Results of performance test}

Several standard weights, ranging from 50 to $1000 \mathrm{mg}$, were put on the impinging plate in sequence to calibrate the test rig. The calibration results are shown in Fig. 5. It can be seen that the test rig exhibits a good linear response to tested force in the order of milli-Newton. 


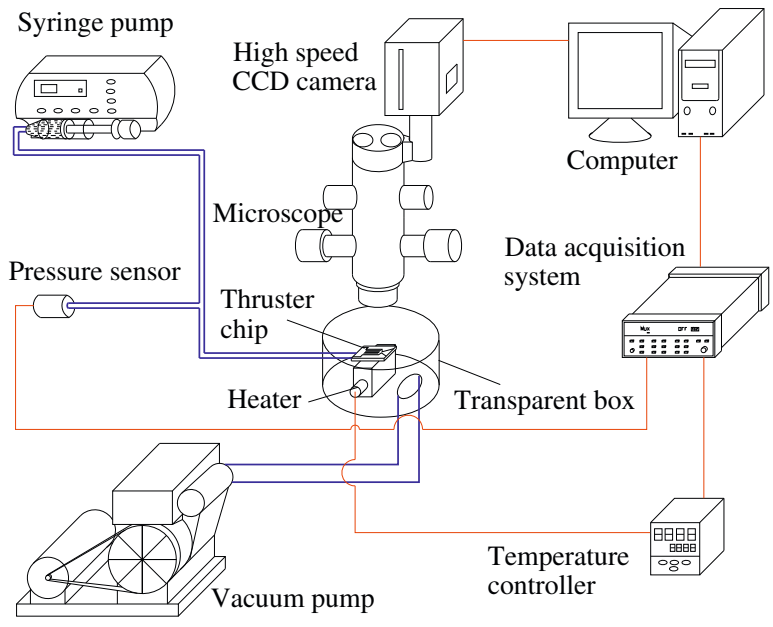

Fig. 4. Visualization experiment set-up.

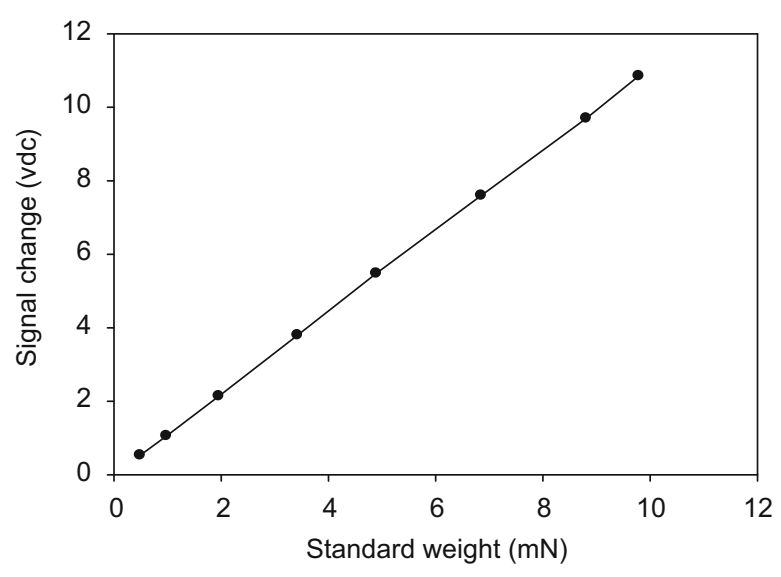

Fig. 5. Calibration results.

The procedure of micro-thrust force measurement was as follows:

(1) The micro-thruster must be preheated to at least about $120^{\circ} \mathrm{C}$ before the valve (as shown in Fig. 2) was opened.

(2) Open the valve and wait for the thruster to reach a stable state, but the nozzle was not aimed at the impinging plate at this time.

(3) Aim the thruster nozzle at the impinging plate for a while.

(4) Move the thruster away from the impinging plate.

After the measurement procedure, there was a squarewave signal recorded by the computer as shown in Fig. 6 .

Due to boiling two-phase flow instability in the thruster, both thrust force and pressure signal were instable. Then their average values were taken as the results. As shown in Fig. 6, $h$ is the average thrust force voltage signal difference between before and after the nozzle aimed at the impinging plate. The average thrust force was obtained through multiplying $h$ by a ratio resulting from calibration. From Fig. 6, the thrust force

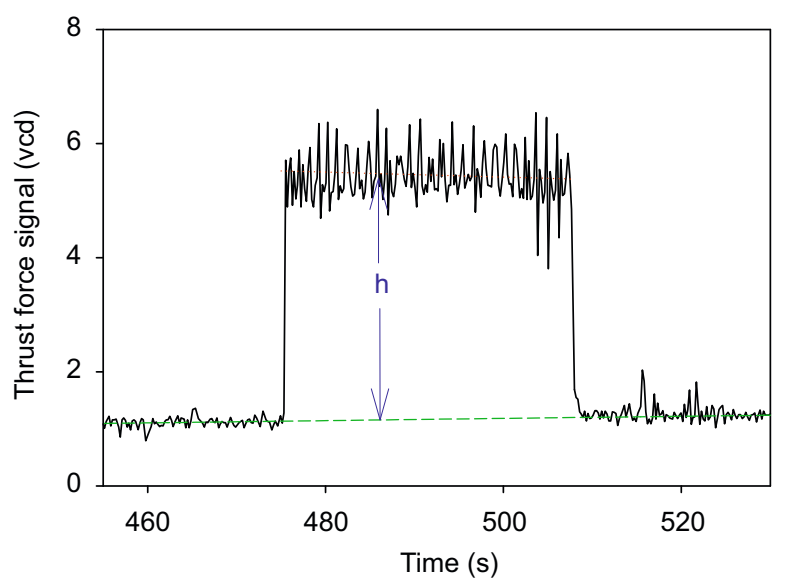

Fig. 6. Thrust force test signal process.

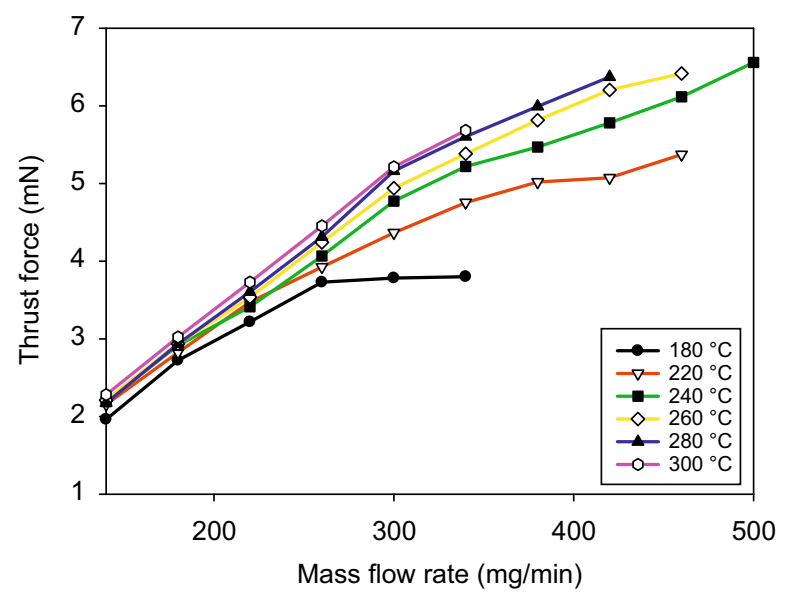

Fig. 7. Variation of thrust force with mass flow rate.

signal shows some levels of randomness. It is very common for thrust test that the micro- or milli-Newton thrust force signal, found in many literatures about microthrust force, shows some levels of randomness because micro-scale thrust force is so small that the ratio of its noise to full thrust force is much larger than the normal scale one. In this paper, no weighting factor was used to calculate the average values. Both average thrust and pressure were simply algebraic averages. About 100-250 data points, lasting 20-50 s in experiments, were used for these averaging, which were enough to get an accurate average data. From analysis on experimental data, the estimated uncertainties of average thrust and pressure values are about $\pm 0.02 \mathrm{mN}$ and \pm 0.01 bar, respectively.

Figs. 7 and 8 present the results of average thrust force and pressure for different temperatures and flow rates, respectively. It can be seen in Fig. 8 that inlet pressure increases with chip temperature at the same flow rate because higher temperature corresponds to higher saturation vapor pressure. And it is obvious that inlet pressure increases with flow rate at the same chip temperature. In addition the increase of the inlet 


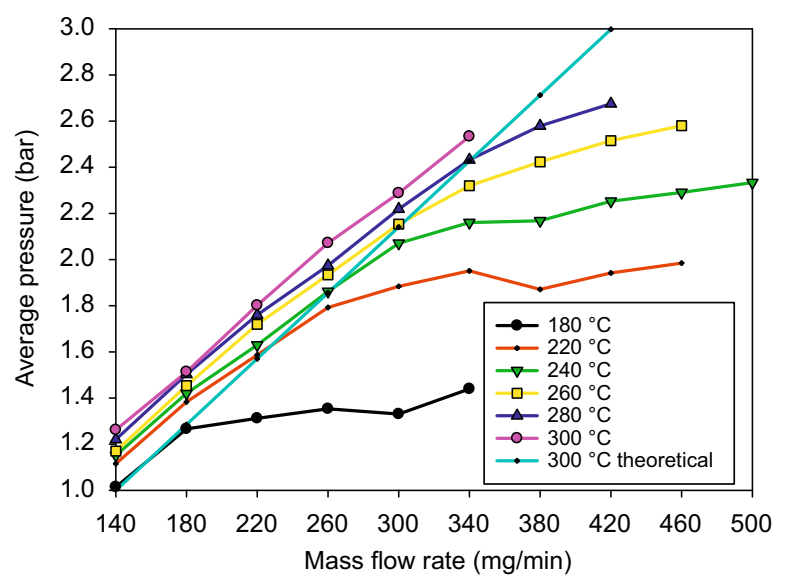

Fig. 8. Variation of inlet pressure with mass flow rate.

pressure slows down when the flow rate becomes higher because the bulk flow temperature decreases.

Because thrust force increases with inlet pressure, the curve of Fig. 7 is similar to that of Fig. 8. Thrust force increases with chip temperature at the same flow rate because water molecule absorbs more energy at higher temperature, and then can reach higher velocity at the nozzle.

Chocked flow must occur at the nozzle due to vacuum environment. According to one-dimensional isentropic flow theory, chocked flow rate is given by [24]

$\dot{m}_{\max }=\frac{P_{0} A_{t}}{\sqrt{\gamma R T}} \gamma\left(\frac{2}{\gamma+1}\right)^{(\gamma+1) / 2(\gamma-1)}$,

where $P_{0}$ refers to total pressure, $A_{t}$ to throat section area, and $\gamma$ to specific heat ratio. According to Eq. (1), chocked flow rate exhibits a linear response to inlet pressure. Given that $T=573.15 \mathrm{~K}, A_{t}=120 \mu \mathrm{m} \times 150 \mu \mathrm{m}=1.8 \times 10^{-8}$ $\mathrm{m}^{2}, \gamma=1.3, R=461.67 \mathrm{~J} /(\mathrm{kg} \mathrm{K})$, theoretical inlet pressure is obtained by this equation as shown in Fig. 8. As can be observed in Fig. 8, the experimental pressure is higher than the theoretical one. The size of the MEMS nozzle is much smaller than the conventional one but thickness of the boundary layer never scales down correspondingly. Therefore, the actual effective diameter of the throat area is reduced. For the same mass flow rate, smaller effective $A_{t}$ leads to larger $P_{0}$ according to Eq. (1).

With the increase of flow rate, the increase of inlet pressure slows down. Then the experimental inlet pressure is much lower than the theoretical one. Furthermore, the lower the chip temperature is, the lower the average pressure will be. This is attributed to the fact that larger mass flow rate cools down the chip and reduces inlet temperature. Some small liquid droplets even flowed out of the nozzle when mass flow rate is too large. It was proved by flow visualization experiment in the following section.

Specific impulse is defined as

$I_{s}=\frac{F}{\dot{m} g}=\frac{v_{e}}{g}$
From the result of the specific impulse presented in Fig. 9 it was observed that a maximum specific impulse is given for a certain mass flow rate.

According to one-dimensional nozzle isentropic flow theory, the nozzle exit velocity is given by

$v_{e}=\sqrt{\frac{2 \gamma R T}{\gamma-1}\left[1-\left(\frac{p_{e}}{P}\right)^{(\gamma-1) / \gamma}\right]}$

Too small inlet pressure $P$ results in low specific impulse, while too large $P$ leads to low fluid temperature and reduces the specific impulse as well.

In this work, the fluid state at the outlet of the nozzle was easily identified by the eye. When doing this experiment, the nozzle was aiming at a sight glass in the vacuum chamber. When the fluid state was full vapor, we could see nothing; when the fluid state was two phase, some droplets flowing out of the nozzle stuck to the sight glass and accumulated on the surface. They soon turned to white tiny ice balls in vacuum due to flash and cooled down quickly; when the fluid state was full liquid, there

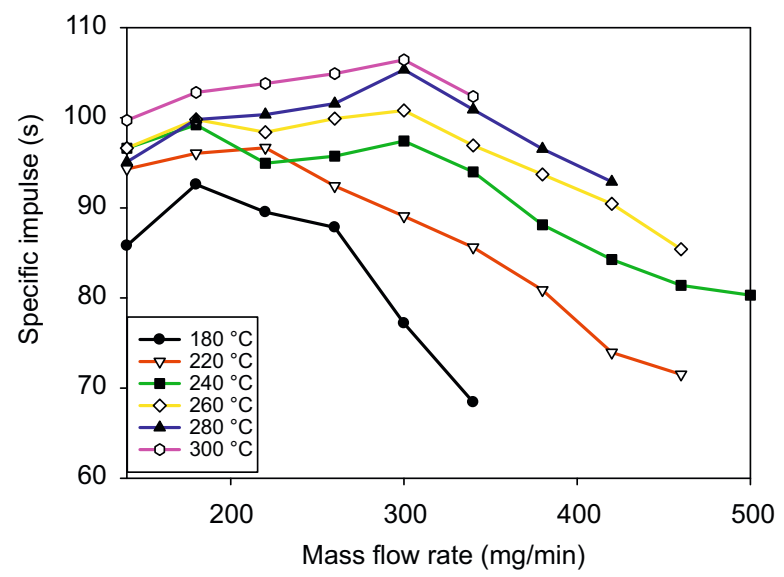

Fig. 9. Variation of specific impulse with mass flow rate.

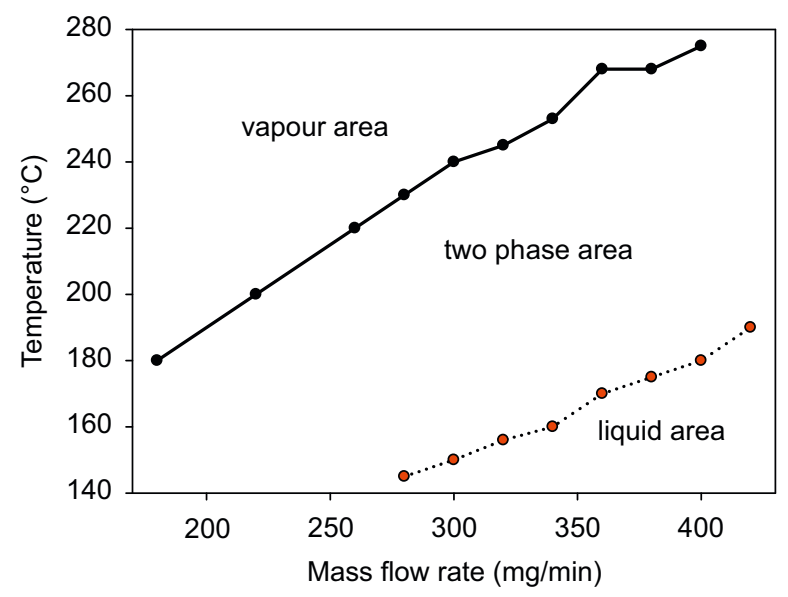

Fig. 10. Fluid state at the outlet of the nozzle. 
was a continuous liquid jet from the nozzle, which was very easy to be observed by the eye.

Of course, fluid state can also be identified by image analysis in principle. But when fluid state is two phase, with this approach it is hard to identify droplets at the nozzle outlet because droplets flow very fast. As mentioned in Section 3.2.1, droplet flow velocity in micro-channels was about $10 \mathrm{~m} / \mathrm{s}$. When droplets are accelerated in Laval nozzle, its velocity may increase up to hundreds of meters per second. In my opinion, expensive instruments are not always more convenient and accurate than human eye or ear.

In this paper, flow rate was set by the syringe pump. The nominal uncertainty of the pump was less than $1 \mathrm{mg} / \mathrm{min}$. Roughly, the uncertainty in Fig. 10 was less than $5 \%$ due to eye observation.

The results of observation are shown in Fig. 10. Fluid state at the outlet of the nozzle can be divided into three areas in the map of temperature versus mass flow rate: (i) liquid area, (ii) two phase area, and (iii) vapor area. VLM have to work in (iii) area to achieve better performance.

\subsection{Results of flow visualization experiment}

\subsubsection{Comparison of flow patterns at the same chip} temperature for different flow rates

Performance test results of specific impulse in Section 3.1 show that there exists a maximum specific impulse for a certain flow rate at the same chip temperature. In order to find out the reason that causes different specific impulses for different flow rates, flow visualization study was carried out at a chip temperature of $280{ }^{\circ} \mathrm{C}$ for three mass flow rates $(300,140,420 \mathrm{mg} / \mathrm{min})$ according to Fig. 9. These flow patterns were compared and analyzed as shown in Figs. 11-13.
The flow rate in Fig. 11 was $300 \mathrm{mg} / \mathrm{min}$, at which specific impulse attained a maximum at a chip temperature of $280{ }^{\circ} \mathrm{C}$ according to Fig. 9. Explosive boiling took place periodically at the joint of inlet square and the micro-channels. It pushed most of the incoming fluid backward and the rest forward into the nine microchannels. Liquid water pushed into the channel conglomerates as droplets due to surface tension. Because of strong viscous effect in micro-scale, droplets clogged the channel. Subsequently, droplets evaporated continually and got smaller. Then, when droplet shrunk small enough, they were pushed out by pressure, and flowed out of the nozzle with vapor.

The flow velocity of droplet being pushed out in microchannel is in the order of $10 \mathrm{~m} / \mathrm{s}$ according to visualization measurement results. The micro-channel is $6 \mathrm{~mm}$ long. Then the residence time of a droplet in the micro-channel is about $0.6 \mathrm{~ms}$. Due to small size and high speed, droplet flow in the micro-channel substantially deviates from thermodynamic equilibrium, and heat transfer in the process is deteriorated. In such a short residence time in micro-channels, droplets must be vaporized completely; otherwise they will flow out of the nozzle in liquid state and result in low specific impulse because the higher the gas molecular velocity is, the higher the specific impulse will be. The exit velocity is given by [25]

$$
v_{e}=c_{0} \frac{M_{e}}{\left(1+(\gamma-1 / 2) M_{e}^{2}\right)^{1 / 2}}
$$

Here, $c_{0}=\sqrt{\gamma R T_{0}}$ is stagnation sound velocity and $M_{e}$ is exit Mach number. According to Eq. (4), $v_{e}$ can be considered as a function of $M_{e}$, that is $v_{e}=c_{0} f\left(M_{e}\right)$. Function $f\left(M_{e}\right)$ depends on the area ratio of the nozzle $A_{e} / A_{t}$, and its dependence on specific heat ratio can be neglected because of small variation range of $\gamma$. Therefore, for a nozzle with certain size, we have $v_{e} \propto c_{0}$, approximately.

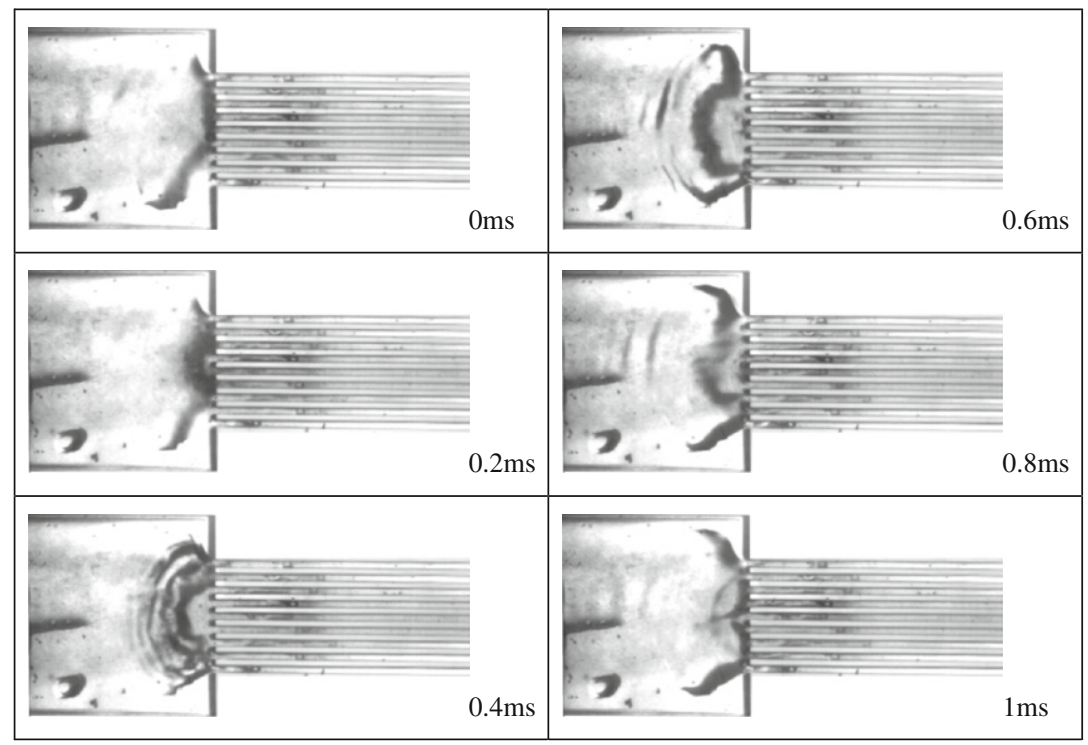

Fig. 11. Flow pattern of the biggest specific impulse at a chip temperature of $280{ }^{\circ} \mathrm{C}$ when mass flow rate is optimal, $300 \mathrm{mg} / \mathrm{min}$. 


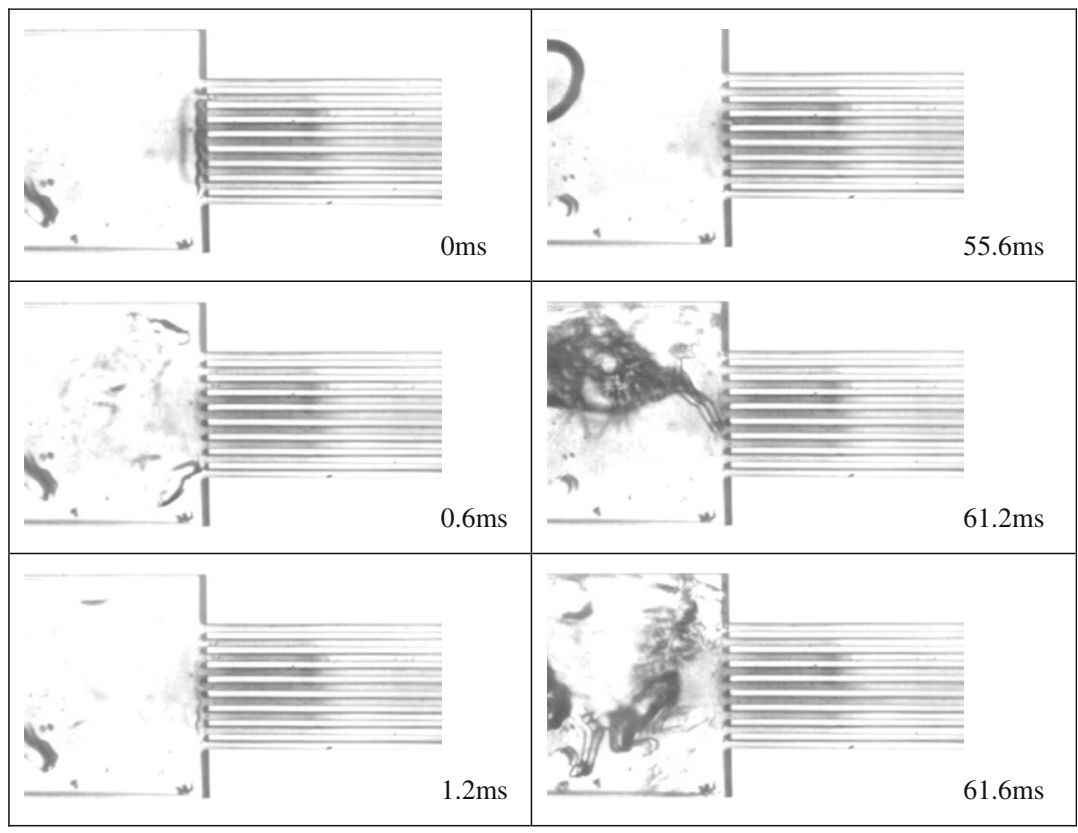

Fig. 12. Flow pattern of lower specific impulse at a chip temperature of $280^{\circ} \mathrm{C}$ when mass flow rate is too small, $140 \mathrm{mg} / \mathrm{min}$.

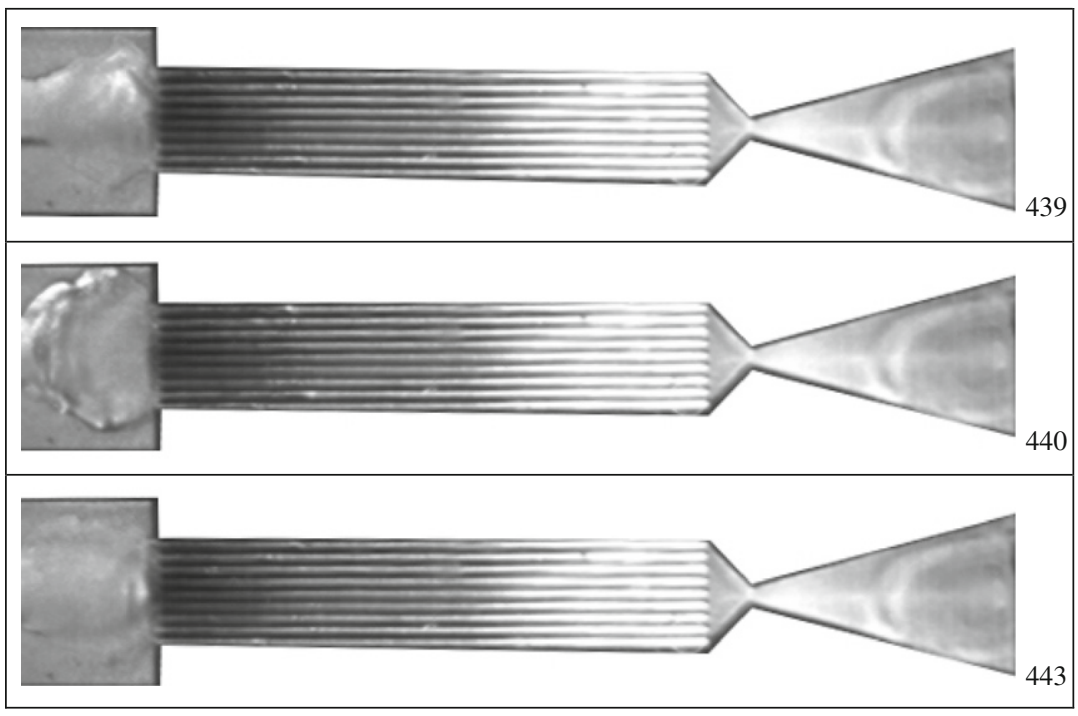

Fig. 13. Flow pattern of lower specific impulse at a chip temperature of $280^{\circ} \mathrm{C}$ when mass flow rate is too large, $420 \mathrm{mg} / \mathrm{min}$.

For a certain $T_{0}$, we get,

$v_{e} \propto \frac{1}{\sqrt{M}}$

That is to say, propellant of smaller molecular can achieve higher exit velocity and produce higher specific impulse. Fluid flows out of the nozzle in the form of mist if droplets are not vaporized completely in micro-channels. Mist is equivalent to very large "molecular". Therefore, its exit velocity is much lower than gas molecular.

Thus, at a certain heating temperature, a microthruster should have appropriate length of flow channel to make droplets vaporize sufficiently and to produce high specific impulse.

In Fig. 12, mass flow rate was $140 \mathrm{mg} / \mathrm{min}$, which was much less than $300 \mathrm{mg} / \mathrm{min}$ at which the highest specific impulse was attained. Interval explosive flow pattern took place in the square inlet. The square inlet was dried out at times. Fewer droplets clogged in micro-channels, and most of them were located near the square inlet than that of Fig. 11. Although water was vaporized more sufficiently, the flow rate was too small, and vapor pressure was also too low, then specific impulse was low.

Mass flow rate in Fig. 13 was $420 \mathrm{mg} / \mathrm{min}$. Its flow pattern was similar to that of Fig. 11. But liquid water 
flowed deeper into the micro-channels (the dark part of the micro-channels denotes liquid), and then droplet flow distance was reduced. Therefore, droplet could not be heated and vaporized sufficiently.

\subsubsection{Analysis of several flow boiling types in the micro- thruster chip}

Flow boiling is the most important process in a VLM. In this section, we analyzed several flow boiling patterns that occur in flow visualization experiment.

The chip temperature in Fig. 14 was very low, about $120^{\circ} \mathrm{C}$. When an extremely small gas bubble with a diameter of less than $0.03 \mathrm{~mm}$ flowed into the chip inlet, it expanded only a little bigger to about $0.1 \mathrm{~mm}$ diameter during the first $38 \mathrm{~ms}$. After that the bubble expanded rapidly to about $1 \mathrm{~mm}$ in diameter within $1 \mathrm{~ms}$. Then it was sucked into one of the micro-channels. This figure indicates that: (i) small bubbles, may be an insoluble gas bubble, can exist in the liquid for a relatively long time; (ii) bubble expands quickly after its size exceeded a critical value. Meanwhile, at the same condition of Fig. 14 (flow rate: $220 \mathrm{mg} / \mathrm{min}$, temperature: $120^{\circ} \mathrm{C}$ ), we observed that some vapor produced in micro-channel flowed back into the square inlet and was sucked into another channel.
Fig. 15 shows that when chip temperature was high, about $280^{\circ} \mathrm{C}$, liquid water vaporized suddenly once it touched the joint of square inlet and micro-channel where the structure in the chip was the most complex. Large amount of vapor produced in such a short time and in such a tiny volume caused an explosive boiling phenomenon. This phenomenon took place periodically. Its period was only about $1 \mathrm{~ms}$. Explosive boiling pushed most of the liquid back, and squashed some into microchannels. The phenomena indicate that boiling tends to take place where structure is complex. Therefore, when a new VLM is designed, the flow groves should be as complex as possible, for example, micro-pillar array, etc. to facilitate boiling and improve its thrust performance.

The flow rate and chip temperature in Fig. 16 were $140 \mathrm{mg} / \mathrm{min}$ and $160^{\circ} \mathrm{C}$, respectively. Droplets stopped at the center of the square inlet occasionally for a while (about $30 \mathrm{~ms}$ ), absorbing heat and becoming superheat. Then, it exploded suddenly within a very short time, usually less than $0.2 \mathrm{~ms}$. $0.2 \mathrm{~ms}$ was the finest solution that the high speed camera can acquire, and the phenomena may take place less than $0.2 \mathrm{~ms}$. The droplet exploded and evaporated quickly at the square inlet. This type of boiling indicates that boiling in micro-scale is not so continuous as that in normal scale does.

Fig. 17 is an interesting boiling phenomenon associated with a tiny taint. The temperature and flow

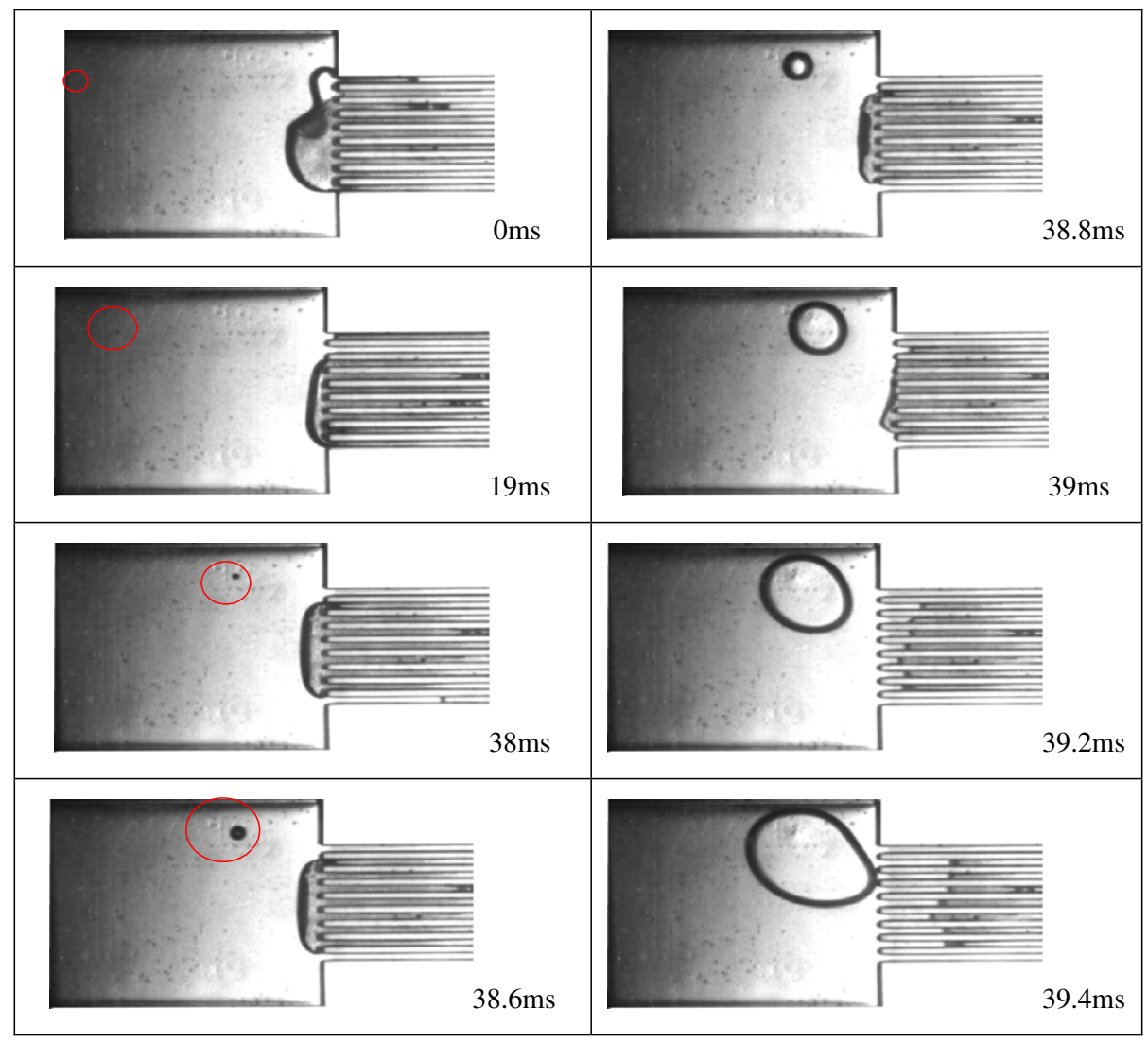

Fig. 14. Bubble gradual growth at low chip temperature, about $120^{\circ} \mathrm{C}$. 


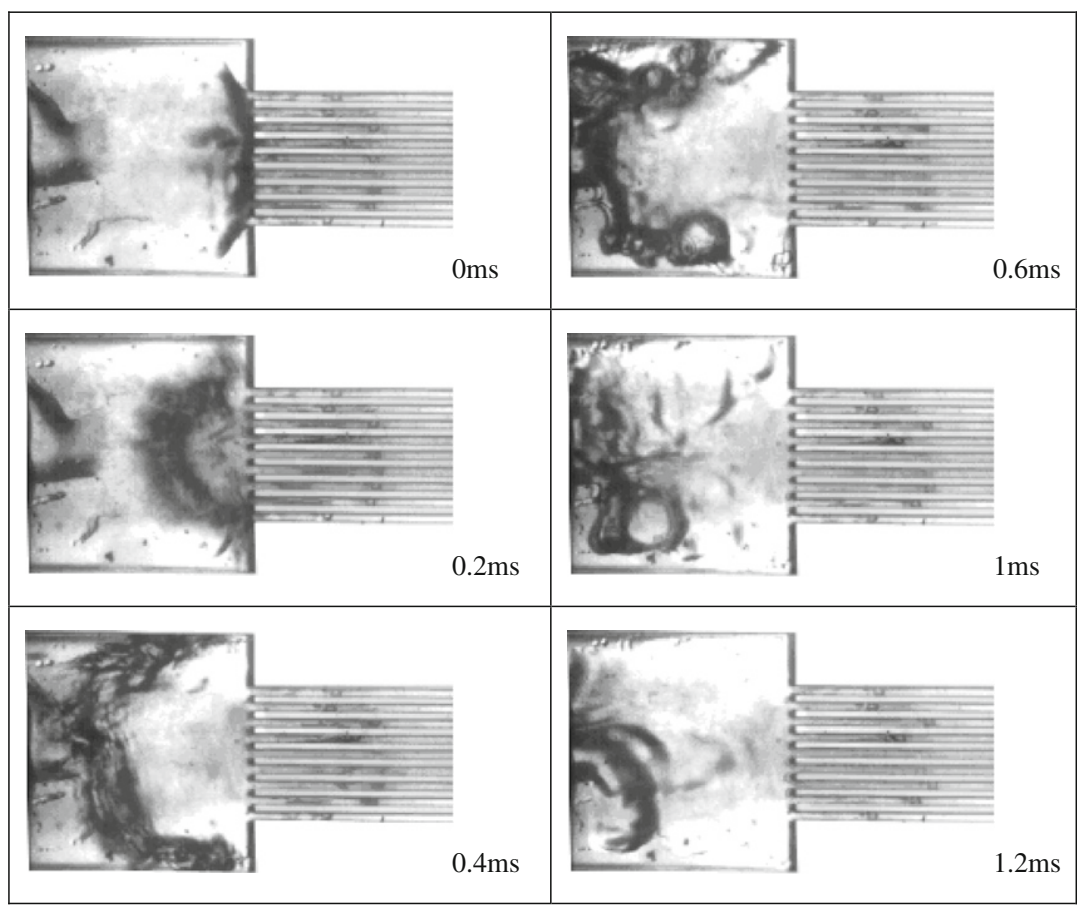

Fig. 15. Explosive boiling phenomena.

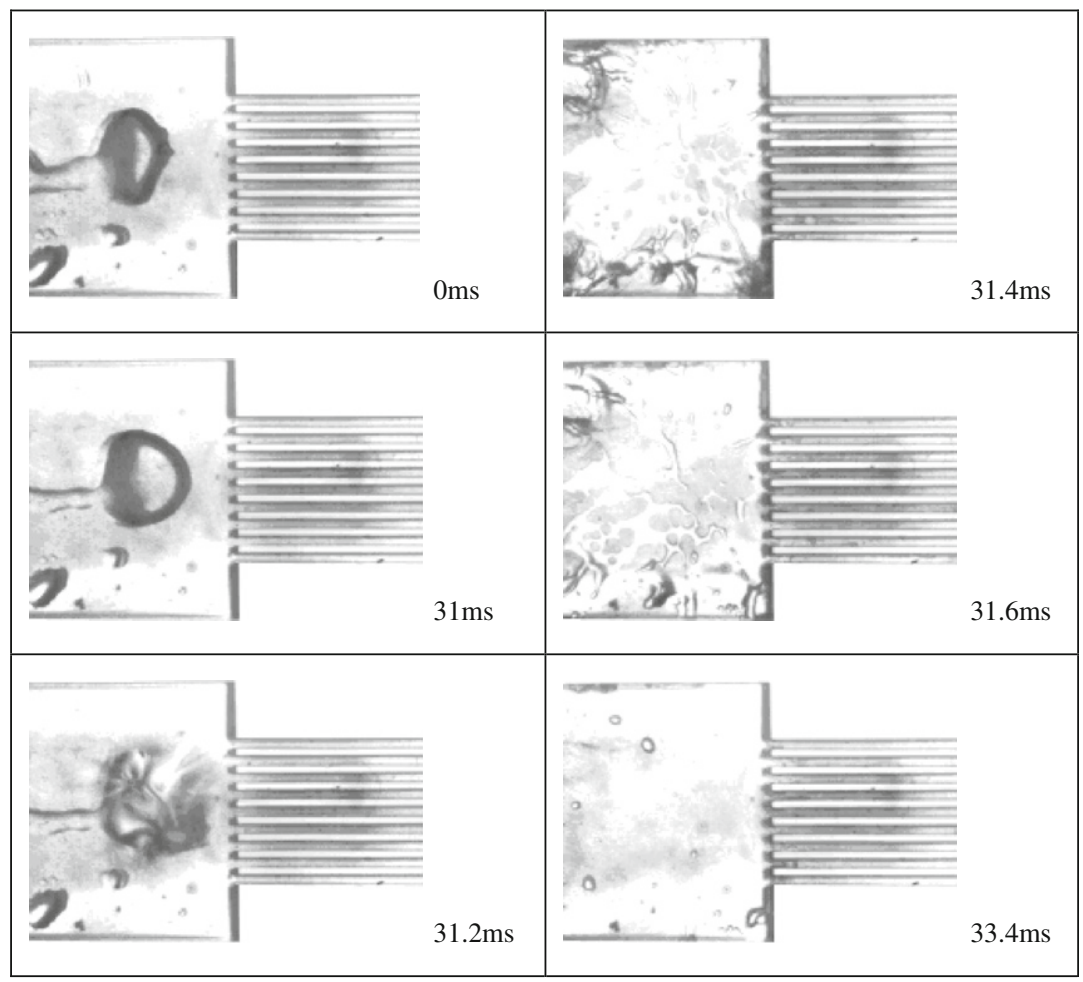

Fig. 16. Droplet explodes suddenly in square inlet.

rate in Fig. 17 were $280^{\circ} \mathrm{C}$ and $140 \mathrm{mg} / \mathrm{min}$, respectively. The taint was occasionally located at the square inlet. It tended to act as a cavity for nucleate boiling. Vapor was produced more easily at the taint than at other places. Vapor spread out from it and cool water supplemented back to it. Then a beautiful vapor halo around the taint 


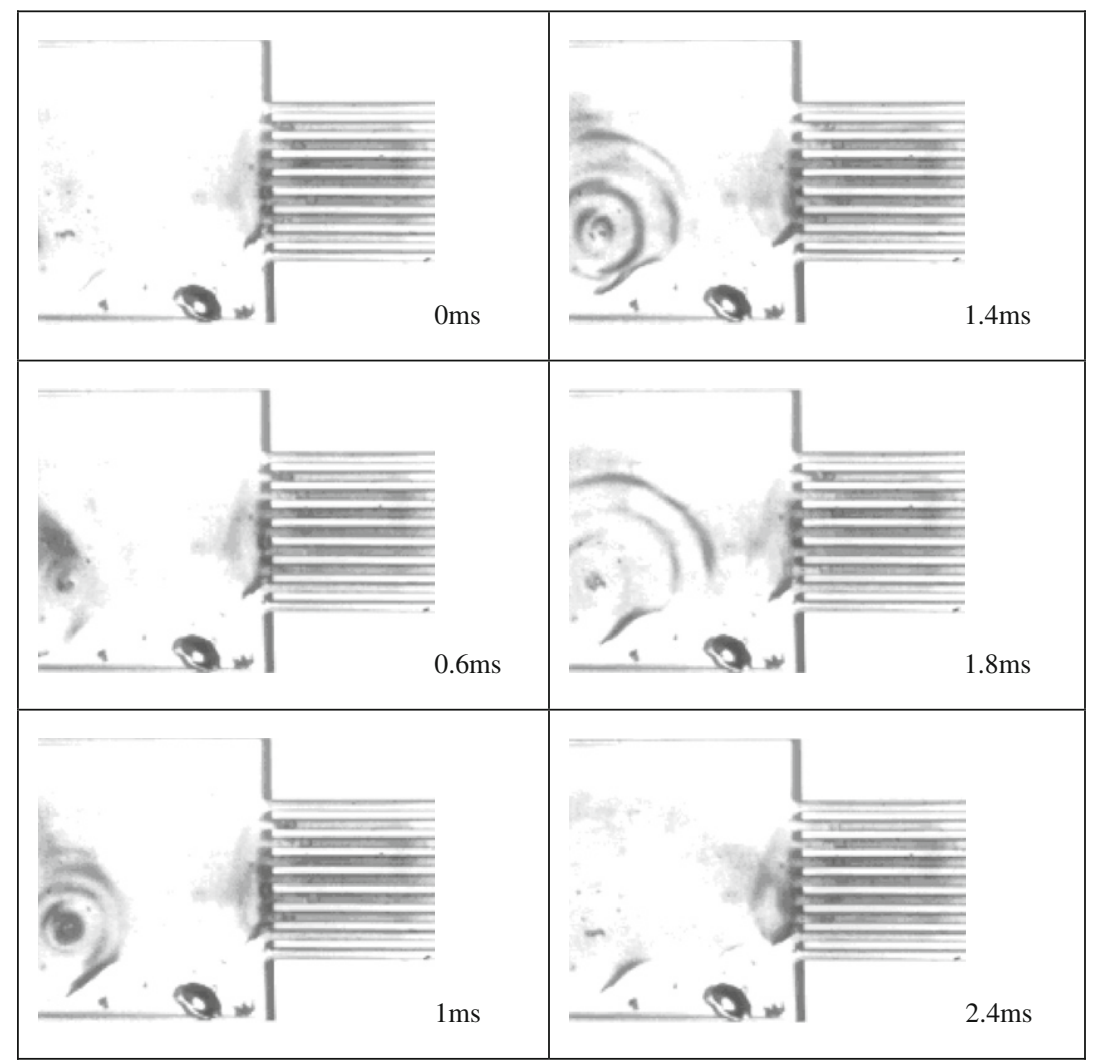

Fig. 17. Vapor halo around a tiny spot at the square inlet.

appeared. It was probably because that bubble produced at the taint is trapped in the $120 \mu \mathrm{m}$ deep fluid grove, which is smaller than its departure diameter, and then the bubble is forced to spread out horizontally in the form of circles. Each round of gas circle in the halo is equivalent to a bubble leaving the spot.

\subsubsection{Discussion of boiling in the micro-thruster chip}

The superheat temperature of onset nucleate boiling in micro-channel is given by [25]

$\Delta T_{\text {sat,ONB }}=\frac{8 \sigma T_{\text {sat }} v_{f g} C}{D_{h} h_{f g}}$

For a micro-channel of a hydraulic diameter larger than $1 \mathrm{~mm}$, small superheat is needed. But when the channel became smaller, larger superheat is required for onset boiling. Square inlet needs high superheat because of its planar geometry (as shown in Fig. 16). But when water touched the joint of square inlet and microchannels where there were sharp corners (as shown in Fig. 11) or occasional taints (as shown in Fig. 17) or there existed a insoluble gas bubble (as shown in Fig. 14), boiling usually took place more easily.

Once boiling starts, large superheat energy released, causing the bubble to expand rapidly or even explode, pushing upstream liquid water back. Several boiling types stated above indicate that boiling in micro-scale takes place once at a time instead of in continuous mode as normal scale does.

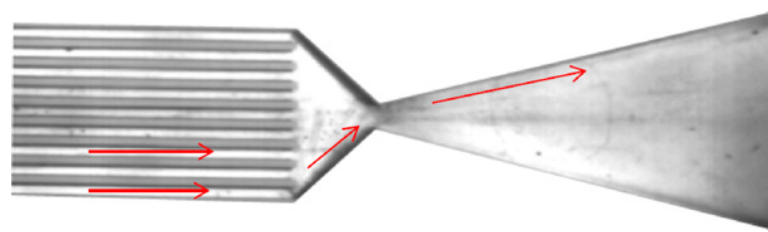

Fig. 18. Schematic flow of deflection in micro-nozzle.

\subsubsection{Thrust deflection in micro-nozzle}

Droplets flowing through side channels spurted out of the micro-nozzle, deflected to the other side. The flow path is schematically shown in Fig. 18. The phenomena cause thrust vector deflects from the nozzle symmetry axis and reduce effective axial thrust. The phenomena can be observed more easily in moving pictures.

Thrust deflection also occurs in the condition that full liquid ejection: the liquid jet deflects from the nozzle axis. Changing inlet pressure will change jet direction.

In the case of full gas jet, thrust deflection may still occur in micro-nozzle. Choudhuri et al. [26] found thrust deflection in a micro-cold gas thruster by schlieren. There were no micro-channels at the upstream of the laval nozzle in their thruster. They considered that the asymmetry flow field in the MEMS nozzle was caused by flow perturbation. But in our opinion, the asymmetry of flow field induces from the slight asymmetry of nozzle geometry because micro-scale device is not easy to be 
fabricated symmetrically. The phenomena cause part of thrust vector loss and degrade thrust performance. In addition, if the axis of thrust does not go through the mass center of the satellite or spacecraft, a torque will be formed and make the satellite or spacecraft turn around.

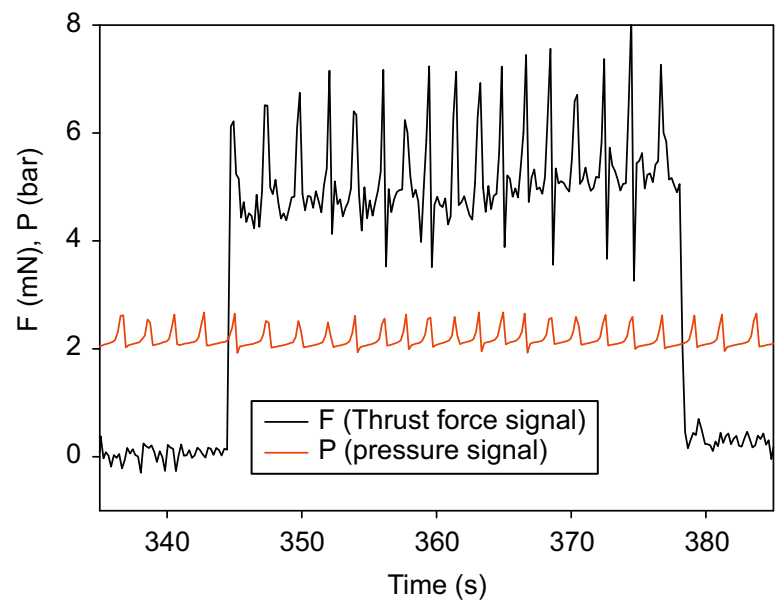

Fig. 19. The impulse of thrust force is consistent with that of inlet pressure.
This kind of turning around with uncertain magnitude and direction is very harmful to high precision attitude control of a satellite.

Thrust deflection may be a general phenomenon for micro-nozzle due to the relatively less symmetry geometry and more severe viscous effects. Therefore, more attention should be paid to eliminate or reduce the deflection effect in micro-nozzle design and fabrication. For instance, adding a parallel section to the nozzle outlet may relief thrust deflection effect.

\subsection{Instability}

\subsubsection{Instability phenomena in VLM}

Two phase flow boiling in a thruster is usually instable. It can be observed in Fig. 19 that frequency and phase angle of thrust and pressure impulse match very well. Pressure impulse induces thrust impulse. Due to the small size of the micro-nozzle, the thrust impulse phase angle is almost the same as that of pressure impulse. Thrust instability is also harmful to high precision attitude control of micro-satellites.

Periods and amplitudes of pressure impulse in different working conditions are summarized in Table 1. From this table, it can be concluded that: (i) at the same flow

Table 1

Static on pressure impulse period and amplitude.

\begin{tabular}{|c|c|c|c|c|c|c|c|c|c|}
\hline$T\left({ }^{\circ} \mathrm{C}\right)$ & $M(\mathrm{mg} / \mathrm{min})$ & 160 & 180 & 200 & 220 & 240 & 260 & 280 & 300 \\
\hline \multirow[t]{2}{*}{140} & Periods (s) & 0.667 & 0.53 & Short & Short & Short & Short & Short & Short \\
\hline & Amplitude (bar) & 0.11 & 0.16 & 0.172 & 0.2 & 0.22 & 0.31 & 0.33 & 0.25 \\
\hline \multirow[t]{2}{*}{180} & Periods (s) & 0.741 & 0.541 & Short & Short & Short & Short & Short & Short \\
\hline & Amplitude (bar) & 0.18 & 0.25 & 0.27 & 0.32 & 0.36 & 0.4 & 0.44 & 0.48 \\
\hline \multirow[t]{2}{*}{220} & Periods (s) & 0.952 & 0.638 & 0.526 & Short & Short & Short & Short & Short \\
\hline & Amplitude (bar) & 0.23 & 0.31 & 0.37 & 0.33 & 0.38 & 0.38 & 0.34 & 0.39 \\
\hline \multirow[t]{2}{*}{260} & Periods (s) & 1.25 & 0.555 & 0.488 & 0.454 & Short & Short & Short & Short \\
\hline & Amplitude (bar) & 0.27 & 0.31 & 0.37 & 0.37 & 0.37 & 0.37 & 0.37 & 0.35 \\
\hline \multirow[t]{2}{*}{300} & Periods (s) & 3 & 1.267 & 0.588 & 0.5 & Short & Short & Short & Short \\
\hline & Amplitude (bar) & 0.22 & 0.31 & 0.37 & 0.38 & 0.36 & 0.43 & 0.42 & 0.41 \\
\hline \multirow[t]{2}{*}{340} & Periods (s) & 2.5 & 2 & 0.606 & 0.526 & 0.504 & Short & Short & Short \\
\hline & Amplitude (bar) & 0.24 & 0.27 & 0.32 & 0.4 & 0.33 & 0.38 & 0.41 & 0.47 \\
\hline \multirow[t]{2}{*}{380} & Periods (s) & $\infty$ & $\infty$ & 1.96 & 1.042 & 0.667 & Short & Short & \\
\hline & Amplitude (bar) & 0 & 0 & 0.26 & 0.34 & 0.38 & 0.42 & 0.39 & \\
\hline \multirow[t]{2}{*}{420} & Periods (s) & $\infty$ & $\infty$ & 4.286 & 1.29 & 0.741 & 0.526 & Short & \\
\hline & Amplitude (bar) & 0 & 0 & 0.29 & 0.34 & 0.39 & 0.37 & 0.44 & \\
\hline \multirow[t]{2}{*}{460} & Periods (s) & $\infty$ & $\infty$ & $\infty$ & 1.053 & 0.865 & 0.635 & & \\
\hline & Amplitude (bar) & 0 & 0 & 0 & 0.32 & 0.37 & 0.4 & & \\
\hline \multirow[t]{2}{*}{500} & Periods (s) & $\infty$ & $\infty$ & $\infty$ & $\infty$ & 0.888 & & & \\
\hline & Amplitude (bar) & 0 & 0 & 0 & 0 & 0.37 & & & \\
\hline
\end{tabular}


rate, period decreases with temperature, while amplitude increases and (ii) at the same temperature, both period and amplitude increase with mass flow rate.

In the lower left corner of Table 1, the thruster chip was full of liquid, where the pressure was stable, the period infinite, the amplitude infinitesimal. While in the lower right corner of Table 1, the pressure exceeded the measurement limit of the pressure sensor and no data were recorded. "Short" denotes that period is too short to be identified by data acquisition system.

Fig. 20 presents the evolution of pressure and gas temperature with decreasing chip temperature at a fixed flow rate $(420 \mathrm{mg} / \mathrm{min})$. The temperature of the micro-thruster was set and controlled by a PID controller. When the voltage supplied to electric heater is too large for a certain temperature, the chip temperature will show wavy curves. Preset temperature in the PID controller was used to compare the results.

When doing this experiment, we have also recognized that we had better measure the chip temperature in its stable condition without PID controller. But due to practical reason it was almost impossible to adjust an appropriate applied voltage to the heater and wait a long time for the chip to reach a stable state for every working condition we wanted to measure. In addition, too much water ejected into the vacuum chamber is very harmful for a vacuum pump. Furthermore, in real situation the temperature of VLM should also be wavy when its temperature is controlled by a PID controller and a fixed voltage in micro-satellites. Therefore, PID temperature a

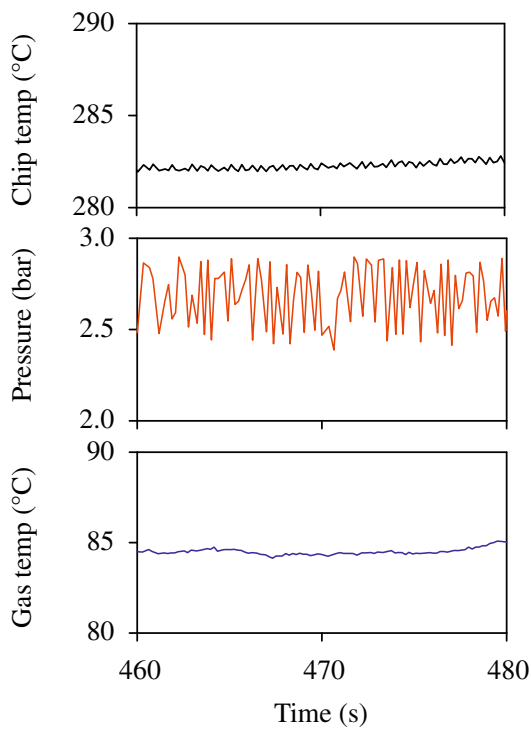

d

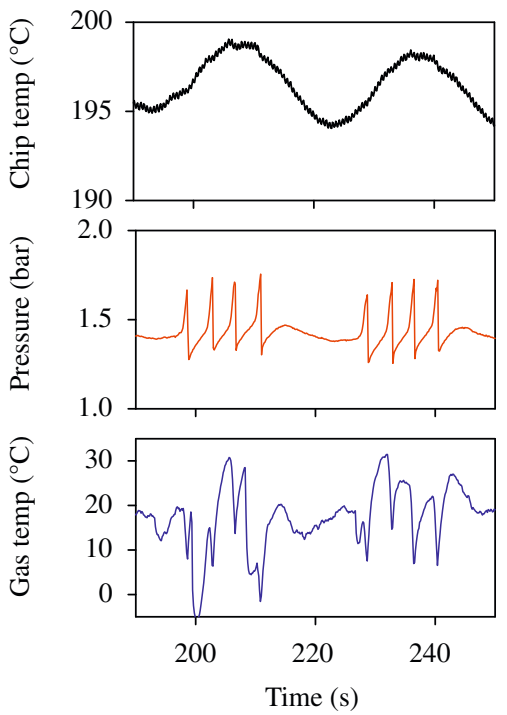

b

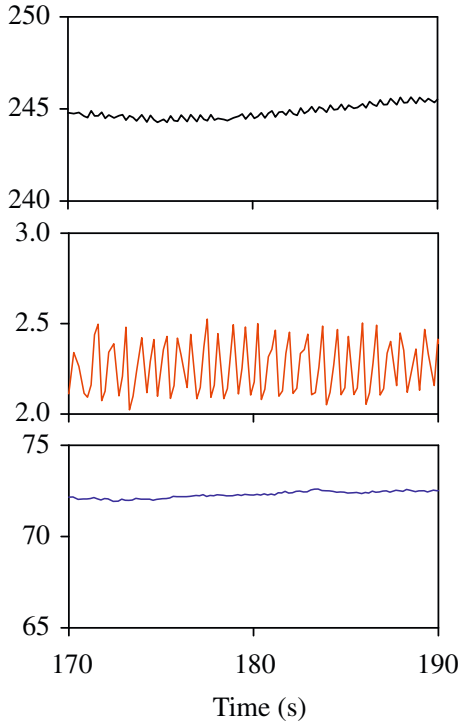

e

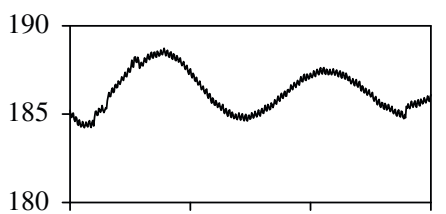

2.0
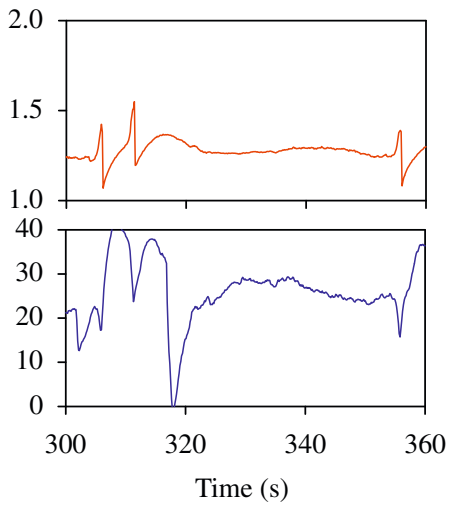

C
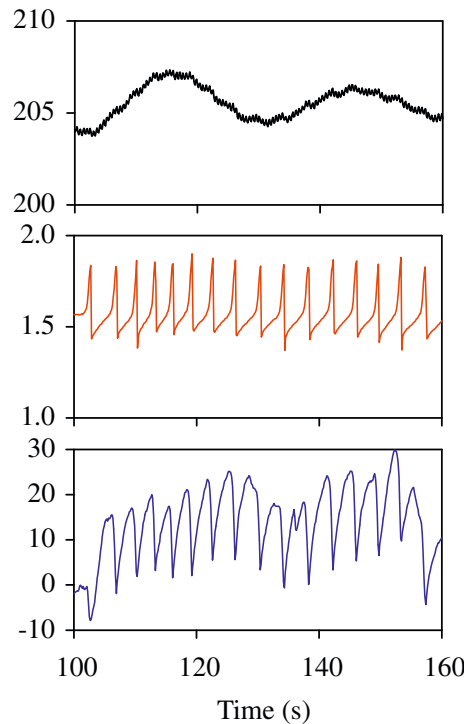

f
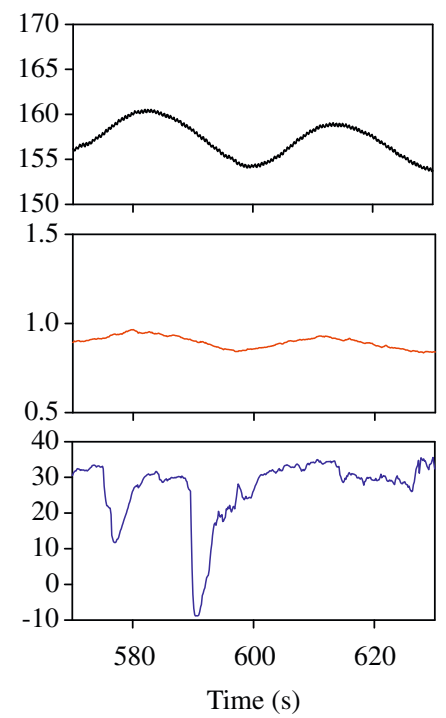

Fig. 20. The evolution of pressure and gas temperature with decreasing chip temperature at a mass flow rate of $420 \mathrm{mg} / \mathrm{min}$. 
control method should be a fast and practical way to conduct this experiment.

Although the temperature profile was wavy, the average thrust and pressure were fortunately much more stable under a certain preset PID temperature control. Therefore, unlike temperature data, average values of thrust and pressure could be considered as time-independent as shown in Figs. 6, 19 and 20a, b. Then PID temperature control had little harmful effect on the investigation on the performance and characteristics of the VLM.

Gas temperature was measured by a K-type thermocouple put at the center of jet stream at a distance of $15 \mathrm{~mm}$ from the outlet of the nozzle.

Fig. 20 also presents a phase angle deviation of about $90^{\circ}$ between gas temperature and pressure impulse. Phase displacement is caused by responding delay of thermal couple. Pressure impulse frequency decreased with decreasing chip temperature, and the impulse stopped finally. When the chip temperature reduced to about $195^{\circ} \mathrm{C}$ as shown in Fig. 20d and e, pressure impulse took place only in the wave crest of chip temperature. At last, liquid spurted out of the nozzle due to low chip temperature, causing the temperature of K-type thermocouple under the nozzle to drop below $0{ }^{\circ} \mathrm{C}$ in vacuum. Magnitude of gas temperature impulse increases with decrease of pressure impulse frequency. The period of pressure signal is caused by two phase flow instability. The period of pressure increased with decreasing chip temperature. The pressure period of Fig. 20a was too short to be identified by the data acquisition system. The pressure period of Fig. 20b and c was about 0.74 and $2.5 \mathrm{~s}$, respectively. Fig. 20d and e were at a critical condition that pressure was going to stop impulse and their periods were hard to define. We did not discuss period at those particular conditions. In Fig. 20f pressure has stop impulse and its period could be considered as infinite.

\subsubsection{Instability analysis and discussion}

From Table 1, it can be concluded that impulse frequency increases with temperature difference between $T_{w}$ and $T_{f}$, and decreases with mass flow rate. The relation can be expressed as

$f \propto \frac{T_{w}-T_{f}}{\dot{m}} \propto \frac{h\left(T_{w}-T_{f}\right)}{(\dot{m} / A) h_{f g}}=\frac{q}{G h_{f g}}=B o$

Then the impulse frequency $f$ can be considered as a function of boiling number.

The impulse of all the variables is caused by the movement of the liquid-gas interface in the microchannel. Kandlikar [27] analyzed this phenomenon and constructed a new dimensionless number.

This dimensionless number, representing the ratio of the evaporation momentum force to the inertia force, is given by

$K=\frac{F^{\prime} w}{F_{I}^{\prime}}=\frac{\left(q / h_{f g}\right)^{2}\left(D / \rho_{G}\right)}{\left(G^{2} D / \rho_{L}\right)}=\left(\frac{q}{G h_{f g}}\right)^{2} \frac{\rho_{L}}{\rho_{G}}=B o^{2} \frac{\rho_{L}}{\rho_{G}}$

The non-dimensional group $K$ includes the boiling number and the liquid to vapor density ratio. The Boiling number alone does not represent the true effect of the evaporation momentum, and its coupling with the density ratio is important in representing the evaporation momentum force. A higher value of $K$ indicates that the evaporation momentum forces are dominant and are likely to alter the interface movement [15]. This theory was validated by our experimental results described above, that is, impulse frequency of variables is related to $B o$ and high $B o$ causes large impulse frequency.

\section{Conclusions}

We studied the performance, flow patterns and instability of a VLM. The following conclusions can be drawn:

(1) The actual effective diameter of the throat area is reduced because thickness of boundary layer never scales down consistently with micro-scale of MEMS nozzle. Therefore, mass flow rate of micro-nozzle is smaller than calculated the one according to one-dimensional isoentropic flow theory.

(2) There exists a maximal specific impulse for different mass flow rates at the same chip temperature. Too small mass flow rate results in low specific impulse. While too large mass flow rate causes vapor temperature decrease and also lowers the specific impulse.

(3) Flow patterns were compared for different mass flow rates at the same chip temperature. Flow pattern of the maximal specific impulse shows that explosive boiling takes place periodically at the joint of inlet square and the micro-channels. There are some droplets clogging at micro-channels near the joint due to strong viscous effect in micro-scale.

(4) Analysis of several flow boiling types in the microthruster chip presents that boiling usually takes place more easily in three situations as follows: (i) the joint of square inlet and micro-channels where there are sharp corners; (ii) occasional stained spot; and (iii) there are insoluble gas bubbles exit.

(5) Structural symmetry of micro-nozzle is not as good as normal size nozzle due to manufacturing difficulty of micro-scale components. Poor symmetry tends to result in thrust deflection. This problem should be especially solved by micro-nozzle design.

(6) Flow boiling in thruster is usually instable. Pressure impulse induces thrust impulse. The amplitude of impulse is increased with both temperature and mass flow rate. Impulse frequency is related to boiling number and high boiling number causes large impulse frequency.

\section{Acknowledgements}

This work was supported by the National Fund for Distinguished Yong Scholars (Grant no. 50825603) and the National Natural Science Foundation of China (Grant no. 50906092). 


\section{References}

[1] D.J. Barnhart, T. Vladimirova, M.N. Sweeting, Very-small-satellite design for distributed space missions, Journal of Spacecraft and Rockets 44 (6) (2007) 1294-1306.

[2] D.L. Hitt, C.M. Zakrzwski, M.A. Thomas, MEMS-based satellite micropropulsion via catalyzed hydrogen peroxide decomposition, Smart Materials and Structures 10 (6) (2001) 1163-1175.

[3] D. Gibbon, J. Ward, N. Kay, The design, development and testing of a propulsion system for the SNAP-1 nanosatellite, in: 14th Annual/ USU Conference on Small Satellites, SSC00-1-3.

[4] E.P. Caillibot, C.C. Grant, D.D. Kekez, Formation flying demonstration missions enabled by CanX nanosatellite technology, in: 19th Annual AIAA/USU Conference on Small Satellites.

[5] R.L. Bayt, K.S. Breuer, Analysis and testing of a silicon intrinsic-point heater in a micropropulsion application, Sensors and Actuators A 91 (2001) 249-255.

[6] C. Rossi, S. Orieux, B. Larangot, et al., Design, fabrication and modeling of solid propellant microrocket-application to micropropulsion, Sensors and Actuators A 99 (2002) 125-133.

[7] J. Lee, K. Kim, S. Kwon, Design, fabrication, and testing of MEMS solid propellant thruster array chip on glass wafer, Sensors and Actuators A 157 (2010) 126-134.

[8] A. Kakami, H. Koizumi, K. Komurasaki, et al., Design and performance of liquid propellant pulsed plasma thruster, Vacuum 73 (2004) 419-425.

[9] B.Q.T. Si, D. Byun, S. Lee, Experimental and theoretical study of a cone-jet for an electrospray microthruster considering the interference effect in an array of nozzles, Aerosol Science 38 (2007) 924-934.

[10] J. Mueller, W.C. Tang, A.P. Wallace, W. Li., D. Bame, I. Chakraborty, R. Lawton, Design analysis and fabrication of a vaporizing liquid microthruster, AIAA Paper 97-3054, Seattle, WA, USA, July 1997.

[11] D.K. Maurya, S. Das, S.K. Lahiri, Silicon MEMS vaporizing liquid microthruster with internal microheater, Journal of Micromechanics and Microengineering 15 (2005) 966-970.

[12] D.K. Maurya, S. Das, S.K. Lahiri, An analytical model of a silicon MEMS vaporizing liquid microthruster and some experimental studies, Sensors and Actuators A 122 (2005) 159-166.
[13] E.V. Mukerjee, A.P. Wallace, K.Y. Yan, et al., Vaporizing liquid microthruster, Sensors and Actuators A 83 (2000) 231-236.

[14] X.Y. Ye, F. Tang, H.Q. Ding, Z.Y. Zhou, Study of a vaporizing water micro-thruster, Sensors and Actuators A 89 (2001) 159-165.

[15] C.C. Chen, C.W. Liu, H.C. Kana, et al., Simulation and experiment research on vaporizing liquid micro-thruster, Sensors and Actuators A 157 (2010) 140-149.

[16] H.Y. Wu, P. Cheng, H. Wang, Pressure drop and flow boiling instabilities in silicon microchannel heat sinks, Journal of Micromechanics and Microengineering 18 (2006) 2138-2146.

[17] J.L. Xu, G.H. Liu, W. Zhang, Seed bubbles stabilize flow and heat transfer in parallel microchannels, International Journal of Multiphase Flow 35 (2009) 773-790.

[18] J.L. Xu, C.X. Zhao, Two-dimensional numerical simulations of shock waves in micro convergent-divergent nozzles, International Journal of Heat and Mass Transfer 50 (2007) 2434-2438

[19] C.X. Lin, V.V.V. Gadepalli, A computational study of gas flow in a DeLaval micronozzle at different throat diameters, International Journal for Numerical Methods in Fluids 59 (2009) 1203-1216.

[20] J.L. Xu, Y. Feng, J.W. Cen, Transient flow patterns and bubble slug lengths in parallel microchannels with oxygen gas bubbles produced by catalytic chemical reactions, International Journal of Heat and Mass Transfer 50 (5-6) (2007) 857-871.

[21] J.W. Cen, J.L. Xu, Research on micro-thrust test in vacuum, Journal of Astronautics 29 (2) (2008) 621-625.

[22] A.J. Jamison, A.D. Ketsdever, E.P. Muntz, Gas dynamic calibration of a nano-Newton thrust stand, Review of Scientific Instruments 73 (2002) 3629-3637.

[23] J.W. Cen, J.L. Xu, A simplification method for micro-thrust test, Acta Aeronautica et Astronautica Sinica 29 (2) (2008) 297-303.

[24] P.A. Thompson, Compressible-Fluid Dynamics, McGraw-Hill, New York, 1972.

[25] C.E. Brennen, Fundamentals of Multiphase Flow, Cambridge University Press, Cambridge, 2005.

[26] A.R. Choudhuri, B. Baird, S. R. Gollahalli, Study of flow through microrocket nozzles, in: 12th Annual Symposium on Propulsion, Propulsion Engineering Research Center (PERC), Ohio Aerospace Institute, Cleveland, OH, October 26-27, 2000.

[27] S.G. Kandlikar, Heat transfer mechanisms during flow boiling in microchannels, Journal of Heat Transfer 126 (2004) 8-17. 